\title{
O FUTURO REPETINDO O PASSADO? DIGITAL RIGHTS MANAGEMENT, TECNOLOGIAS DISRUPTIVAS E O DIREITO AUTORAL BRASILEIRO ${ }^{1}$
}

\section{Jordan Vinícius de Oliveira ${ }^{2}$}

Resumo: $O$ artigo propõe analisar algumas tecnologias disruptivas, a saber, inteligência artificial, contratos inteligentes e blockchain e investigar, a partir do caso do digital rights management (DRM), as lições e desafios para a aplicação dos direitos autorais no plano digital. O quadro metodológico e teórico é constituído respectivamente pelo emprego do conceito de pesquisa qualitativa, em Groulx, e pela afirmativa das quatro modalidades de regulação dos comportamentos, em Lessig. Por meio do estudo de caso do DRM, a pesquisa conclui que a aplicação do direito autoral às criações artísticas em plataformas disruptivas precisa ser reavaliada com vistas a empoderar um prospecto mais público e democrático. Desse modo, embora comportem importantes inovações, as tecnologias com inteligência artificial, contratos inteligentes e blockchain sofrem de uma ausência de maior engajamento social e legal.

Palavras-chave: Blockchain. Contratos inteligentes. Direito autoral. Inteligência artificial. Gerenciamento de direitos digitais.

Sumário: 1. Introdução. 2. Premissas da análise: direitos autorais e tecnologias disruptivas. 2.1 Direitos autorais: uma balança desequilibrada. 2.2 As novas disrupções: inteligência artificial, contratos inteligentes e blockchain. 2.2.1 Inteligência artificial e direitos autorais. 2.2.2 Contratos inteligentes e direitos autorais. 2.2.3 Blockchain e direitos autorais. 3. O que o passado pode nos ensinar: Digital Rights Management e os limites da governança por código. 4 Considerações finais. 5. Bibliografia.

\footnotetext{
1 * O presente trabalho foi realizado com apoio da Coordenação de Aperfeiçoamento de Pessoal de Nível Superior - Brasil (CAPES) - Código de Financiamento 001.

** O autor agradece aos avaliadores da Revista Quaestio Iuris pelas valiosas contribuições no processo de revisão às cegas do artigo.

${ }^{2}$ Bolsista de Doutorado DS/CAPES. Doutorando em Direito Civil pela UERJ/RJ. Mestre em Direito e Inovação (2018) e Bacharel (2016) em Direito pela UFJF/MG. Atuou como Técnico em Informática pela CyberTech Informática SJDR/MG, foi bolsista de iniciação científica do CNPq e de mestrado da CAPES. Atua em temas ligados à intercessão entre Direito e Tecnologia. E-mail: <jordanoliveira@tutanota.com>. E-mail: jordanoliveira@tutanota.com
} 


\section{INTRODUÇÃO}

Em plena segunda metade da década de 90, Clayton M. Christensen (1997, p. xviii) difundia o termo "tecnologias disruptivas" para tratar do potencial transformativo que a comercialização de inovações tecnológicas causaria em empresas e em modelos de negócios. Em contraposição às chamadas tecnologias sustentadoras, voltadas para melhorar o desempenho de produtos estabelecidos no mercado, as tecnologias disruptivas teriam a aptidão de revolucionar um setor e deteriorar a performance de bens já consagrados, graças aos seus atributos mais atrativos de preço, tamanho, simplicidade e praticidade de uso.

Para o autor, a invenção dos transistores, por exemplo, é considerada uma tecnologia disruptiva se comparada às antigas válvulas, pois trouxe uma alternativa mais funcional à indústria eletrônica, depreciando a serventia deste último produto (CHRISTENSEN, 1997, p. xix). Decorridos mais de 20 anos das constatações de Christensen, foi possível acompanhar a expansão da internet, da telefonia móvel e o surgimento da vida interconectada.

Se as possibilidades do mundo digital e das tecnologias disruptivas estão longe de estarem assentadas, a relação do direito autoral para com as mesmas se transforma em tema cuja defasagem de conhecimento é quase certeira: há, sempre, uma tecnologia a qual promete revolucionar o uso de obras protegidas por direitos autorais, como músicas, vídeos, publicações ou programas de computador.

Não resolvidas as discussões sobre o uso de tais obras e a intervenção jurídica na internet, as criações que empregam novas tecnologias como a inteligência artificial, os contratos inteligentes e o blockchain começam a ganhar a atenção das pesquisas e debates sobre o futuro digital e o direito autoral. Como se verá, essas inovações disruptivas prometem uma maior automatização na criação, no licenciamento e no controle do uso de criações intelectuais, de maneira a moldar os comportamentos humanos a partir de diretrizes de design tecnológico. Entretanto, esta foi a exata premissa utilizada para impulsionar a aplicação de uma solução tecnológica cujo uso já é relativamente longevo e conhecido nos estudos de direito autoral: a do gerenciamento de direitos digitais ${ }^{3}$ (conhecida como Digital Rights Management ou, doravante, DRM).

\footnotetext{
${ }^{3}$ Como se verá na seção 3 , entende-se por gerenciamento de direitos digitais um conjunto de prerrogativas de controle tecnológico sobre os usos de obras protegidas por direitos autorais. Exemplo prático de aplicação do DRM foi a delimitação de formato e de uso para arquivos de músicas adquiridos na plataforma iTunes, de modo a controlar o gozo destas obras fora da plataforma (TRESISE et al., 2018, p. 01; 06).
} 
Nesse sentido, a presente pesquisa pretende investigar, a nível teórico e qualitativo, as premissas e possibilidades de uso de cada uma das três tecnologias disruptivas supracitadas e avaliar, a partir da experiência do DRM, quais as principais lições e os desafios para a aplicação dos direitos autorais no plano digital.

Para tanto, a investigação parte de um recorte metodológico qualitativo, exposto por Groulx (2012, p. 95-124), focado em conteúdos bibliográficos e publicamente disponíveis. Em caráter complementar, essa perspectiva é incrementada com o uso do marco teórico das quatro modalidades de regulação do comportamento humano, estabelecidas por Lessig (2006, p. 122 9), quais sejam: a lei, as normas sociais, o mercado e a arquitetura.

A construção deste artigo segue três momentos: a próxima seção visa estabelecer as premissas teórico-metodológicas de análise, bem como firmar uma revisão de literatura sobre direito autoral e sua aplicação junto à inteligência artificial, contratos inteligentes e blockchain. Após estabelecidas estas premissas, a seção 3 tem por intuito examinar o caso do DRM e extrair confluências e lições aplicáveis para o direito autoral frente àquelas novas tecnologias disruptivas. Na seção 4, traça-se uma breve síntese conclusiva.

\section{PREMISSAS DA ANÁliSE: DIREITOS AUTORAIS E TECNOLOGIAS DISRUPTIVAS}

Como sugerido pelo título, esta seção estabelece o substrato basilar da investigação para: (a) dilucidar o quadro teórico e metodológico de análise, (b) fixar uma revisão sobre o propósito e a aplicação dos direitos autorais, bem como (c) investigar as possibilidades e desafios a eles trazidos por tecnologias que empregam inteligência artificial, contratos inteligentes e blockchain.

Para realizar a primeira tarefa, é necessário designar quais as escolhas metodológicas e teóricas sustentam a análise aqui empreendida. Em termos metodológicos, o estudo se pauta em uma concepção de análise qualitativa, disposta por Groulx (2012, p. 117-9). De acordo com este autor, a análise qualitativa proporciona uma nova percepção prática dos problemas sociais. Nesse sentido, ela tem especial adesão às pesquisas sociais por estabelecer instrumentos e parâmetros de gestão prática de problemas, utilizando-se para tanto de uma transposição de conhecimentos interconectados. 
Tal conceito é de especial valia para o presente estudo, uma vez que os fenômenos aqui investigados não são apropriações únicas ou exclusivas do Direito: eles guardam pertinência intrínseca às Ciências da Informação e dialogam com modelos das Ciências Econômicas, Matemáticas e Sociais. É neste movimento de conexão e de releitura que se torna possível trazer novos contornos aos problemas sociais erigidos na sociedade digital.

A aplicação de tais parâmetros metodológicos é complementada graças ao papel das quatro modalidades de regulação de comportamentos humanos, apresentadas pela afirmativa teórica de Lawrence Lessig (2006, p. 122-9). Conforme Lessig, a vida humana em sociedade é moldada graças a quatro elementos principais e em constante interação: lei, normas sociais, mercado e arquitetura.

Por lei, abarca-se os regramentos humanos positivados nas mais variadas ordens sociais. Uma legislação federal, um código de conduta profissional ou mesmo uma convenção de condomínio são formas positivadas de se regular a ação ou abstenção do agir. Por normas sociais, entende-se o conjunto de hábitos e práticas reiteradas em cada grupo social, sem necessária positivação. Condutas de boa convivência, como dizer bom dia ou agradecer por uma gentileza, são bons exemplos. Por mercado, compreende-se todo o complexo de relações de oferta e de demanda de produtos e serviços. Nesse sentido, o oferecimento de um celular cobiçado, pela metade do preço, é um ótimo ilustrativo de estímulo ao comportamento de consumo. Por fim, a arquitetura é o conjunto de estruturas ou códigos que compõem o suporte basilar das instâncias da vida em comunidade. Os 140 (cento e quarenta) caracteres originais do Twitter ou os "textões" do Facebook são ilustrações de como viabilizar maneiras específicas de se comportar e interagir em sociedade.

O que a afirmativa teórica de Lessig pressupõe é uma relação mútua e por vezes conflituosa destes elementos para interferir no agir humano. É necessário ressaltar que o autor observa a importância complementar destas instâncias tanto para a vida no mundo físico quanto para a dimensão virtual (LESSIG, 2006, p. xiii). O préstimo deste conceito se deve à sua inerente compatibilidade com a técnica metodológica para formar uma investigação mais interdisciplinar e adaptada às faculdades de uso de obras protegidas por direitos autorais frente às disrupções digitais. Feitos estes esclarecimentos iniciais, parte-se ao debate teórico sobre o direito autoral e seus principais atributos.

\subsection{DIREITOS AUTORAIS: UMA BALANÇA DESEQUILIBRADA}


Consoante Menell e Scotchmer (2005, p. 03), os chamados direitos de propriedade intelectual têm por característica a não-rivalidade no uso, de maneira que, ao contrário de uma propriedade física, o desfrutar de uma criação intelectual não implica em limitação ao gozo de outrem. Dessa maneira, o mecanismo dos direitos de propriedade intelectual age para reverter a lógica natural de não-rivalidade, possibilitando a exclusão de terceiros para garantir ao detentor os direitos únicos de controle sobre determinada obra.

No mesmo sentido, para Boldrin e Levine (2008, p. 176) os direitos de propriedade intelectual, como os direitos autorais, não protegem as invenções intelectuais enquanto ideias, mas somente a expressão das mesmas sobre um meio físico ou virtual. Desse modo, a principal serventia para a concessão de tais direitos é a de estabelecer, aos seus detentores, o controle máximo sobre a cópia dessa expressão criativa. Os pesquisadores argumentam, portanto, que a nomenclatura correta seria direitos de monopólio intelectual, uma vez que sua principal função é a de manter uma exclusividade.

Assim, como a propriedade intelectual é um termo amplo e que se refere a um conjunto de direitos de controle, é necessário ressaltar que o presente estudo possui recorte para o âmbito dos direitos autorais. Não se incluem nesta análise, portanto, os demais mecanismos de controle jurídico sobre criações intelectuais, como patentes, marcas e outros.

Um primeiro passo pertinente ao se trabalhar o direito autoral está contido nas justificativas para a sua concessão e proteção por parte de Estados e Organizações internacionais. Nesse ponto, Ramalho (2017, p. 14-5) fornece importantes esclarecimentos ao explicar a existência de dois argumentos centrais para justificar a existência destes direitos: o natural e o utilitário.

$\mathrm{O}$ argumento de justificação natural expõe em síntese que, elaborada uma obra, há o dever estatal imediato de protegê-la concedendo direitos de exclusividade, por dois grandes motivos: o desforço intelectual ou o atributo pessoal por parte do autor. Os adeptos da noção de desforço empregam pressupostos (lockeanos) de que as prerrogativas de exclusividade surgem como recompensa pelo trabalho intelectual efetuado. Já os adeptos da noção de atributo pessoal afirmam, em suma, que uma criação intelectual é, por excelência, uma extensão natural da personalidade do autor e que merece guarida por parte do Estado (RAMALHO, 2017, p. 14).

Por sua vez, o argumento de justificação utilitário interpreta o direito autoral enquanto meio para promover o bem-estar social, sendo a principal serventia do monopólio de exploração, concedido ao autor, a de promover o incentivo a outros autores para também criarem, causando um despertar de contribuições à cultura geral (RAMALHO, 2017, p. 15). 
Nesse sentido, Souza (2011, p. 664-6) realça a adesão da ordem jurídica brasileira à função promocional dos direitos autorais - decorrente da supracitada visão utilitária destes direitos, com o fornecimento de mecanismos de exclusividade e incentivo ao incremento do patrimônio cultural - em cooperação com a chamada função social. Esta última função seria responsável por salvaguardar, com o amparo de dispositivos constitucionais e infraconstitucionais, o estabelecimento de restrições ao direito de exclusividade.

Trata-se de um mecanismo de equilíbrio, onde o gozo dos direitos autorais recebe contenções intrínsecas (como os limites, as exceções e os prazos dispostos na própria lei) e extrínsecas (perante outros direitos, como os direitos de liberdade de expressão, de educação, de informação, entre outros). Souza destaca, ainda, a importância de se resgatar o olhar sobre o papel do domínio público enquanto elemento da função social, capaz de balancear e potencializar os interesses privados em prol do acesso à informação e da capacidade criativa (SOUZA, 2011, p. 670-8).

Para além das justificações, um segundo passo na compreensão dos direitos autorais se dá a partir da definição de sua natureza jurídica. De acordo com Branco (2013, p. 06-24), a construção jurídica desses direitos deve observar a união de duas categorias distintas: os direitos morais e os direitos patrimoniais. Os direitos morais melhor seriam definidos como direitos pessoais, pois seus privilégios não envolvem apenas dimensões éticas personalíssimas e podem ser exercidos por terceiros que não o autor: um exemplo é o direito moral de modificar uma obra autoral, cujas prerrogativas podem ser usufruídas pelo autor, mas também por terceiros legalmente legitimados. Em seu turno, os direitos patrimoniais melhor seriam definidos como direitos de exclusivo, pois não incorporam todas as faculdades contidas no direito de propriedade. Estes direitos de exclusivo estariam ligados ao aproveitamento econômico sobre a obra.

Importante distinção entre estes dois feixes de direitos está no fato de que, para o sistema autoral vigente no país, os direitos morais podem ser exercidos pelo autor ou por interessados legais mesmo após decorrido o prazo de proteção da obra, com a sua ascensão ao domínio público (BRANCO, 2013, p. 24-6). Assim, por exemplo, caso uma obra com prazo de proteção patrimonial expirado venha a sofrer uma alteração jocosa por outrem, o autor pode se utilizar da dimensão moral do direito autoral para acionar este terceiro judicialmente e requerer providências obrigacionais.

Feitos os esclarecimentos de justificação e de natureza dos direitos autorais cumpre, em último passo, analisar a forma de aplicação destes direitos em plena sociedade da informação. 
Ainda que o direito autoral esteja classificado enquanto uma categoria específica de propriedade intelectual, as obras contidas no seu escopo não possuem uma natureza uniforme.

No contexto legislativo brasileiro, o direito autoral pretende regulamentar programas de computador ${ }^{4}$, imagens, vídeos, músicas, pinturas e textos científicos. Da mesma forma, pretende abarcar em seu espectro de proteção os sermões, as cartas geográficas, os dicionários, as obras litográficas ${ }^{5}$, os projetos, esboços ou obras plásticas de arquitetura, entre outros. Trata-se de uma lógica onde o controle e a restritividade da obra são a regra: após a expressão da ideia em um meio físico ou virtual, assegura-se, de forma automática, que todos os seus direitos estejam reservados ${ }^{6}$.

Conforme Lemos (2005, p. 183-6), as normas de direitos autorais passaram por um processo de enrijecimento a partir das transformações digitais que ocorreram, sobretudo, a partir dos anos 90. Esse processo deturpou os propósitos de incentivo às criações e de propagação das obras na cultura, tendo se desdobrado em maiores privilégios aos detentores de direitos autorais, principalmente grandes indústrias intermediárias, com a propulsão de modelos de negócio ultrapassados.

Segundo Lessig (2003, p. 771-5), o cenário autoral contemporâneo representa um verdadeiro caso em que "dinossauros controlam a evolução". O autor entende que as regras de direito autoral são manejadas principalmente a partir do interesse de grandes corporações, as quais detêm o controle sobre ambientes de criação intelectual e estão aptas a promover o descompasso entre as possibilidades tecnológicas e as diretrizes autorais.

No mesmo sentido, Gracz (2013, p. 40-1) aponta a ausência de sintonia entre leis que regulam obras autorais e os costumes sociais para utilizá-las. A autora constata que o direito autoral pretende lançar mão das mesmas lógicas aplicadas ao mundo de criações físicas para o plano de criações virtuais, o que implica numa dessimetria entre os planos legal e social.

Por fim, como explicam Feres e Oliveira (2016, p. 19-20) e Feres et al. (2018, p. 420-1), a aplicação prática dos direitos autorais tem se desdobrado em mecanismos autoritários de restrição do conhecimento, na contramão das aspirações da sociedade cibernética. Estes autores demonstram o surgimento de iniciativas cujo propósito é o de reverter a lógica máxima de controle sobre a obra, a exemplo das licenças creative commons, do movimento de acesso livre

\footnotetext{
${ }^{4}$ Os programas de computador são regulados pela Lei de Softwares, Lei 9.609/98 e, no que couber, pela Lei de Direitos Autorais, Lei 9.610/98 (BRASIL, 1998).

${ }^{5}$ Segundo o dicionário online Michaelis, a litografia é a "arte ou processo de produzir um desenho, caracteres etc. em uma pedra plana, especialmente preparada, e por meio desta reproduzi-los em papel” (MICHAELIS, 2016).

${ }^{6}$ Vide artigo $7^{\circ}$ da Lei de Direitos Autorais, que inclui as obras supracitadas em um rol exemplificativo de treze incisos de criações intelectuais a serem protegidas (BRASIL, 1998).
} 
e, no plano de programas de computador, das iniciativas colaborativas de software livre ${ }^{7}$. O propósito destas inovações não consiste em abolir o direito autoral, mas utilizá-lo a partir de um molde mais flexível e coerente aos tempos interconectados em que se vive.

\subsection{AS NOVAS DISRUPÇÕES: CONTRATOS INTELIGENTES, BLOCKCHAIN E INTELIGÊNCIA ARTIFICIAL}

Como visto na seção anterior, o próprio aflorar de uma sociedade digital e o surgimento da internet configuraram-se como hábeis a desafiar a aplicação prática dos direitos autorais.

O meio cibernético em si possui uma característica vital que permitiu o surgimento de tantas inovações: a capacidade generativa. De acordo com Zittrain (2006, p. 1.975-1.980), o caráter generativo da Internet e dos computadores reside em sua arquitetura, capaz de incorporar a colaboração de inovações provenientes de terceiros, de forma descentralizada. É, por exemplo, a partir da generatividade que programas de computador e aplicativos de celular surgem com velocidade exponencial, mesmo que seus desenvolvedores não tenham qualquer direito ou vínculo junto aos criadores das plataformas nas quais suas criações serão executadas.

Graças a este caráter generativo, a internet e os microcomputadores permitiram o surgimento de tecnologias capazes de despertar um misto de entusiasmo e receio por parte de empresas, governos e da sociedade em geral. Se as melhorias e as complicações trazidas ao direito autoral pelo meio cibernético estão longe de serem consideradas como estabilizadas, uma nova onda tecnológica oriunda da generatividade promete trazer ainda mais desafios ao Direito e, sobretudo, aos direitos autorais. Analisa-se agora o que são e quais implicações a inteligência artificial, os contratos inteligentes e o blockchain podem trazer ao cenário autoral.

\subsubsection{Inteligência artificial e direitos autorais}

Por inteligência artificial, é necessário destacar de início que não há uma definição unânime. Entretanto, Calo (2017, p. 02-5) oferece um substrato conceitual simples ao afirmar que, em verdade, fala-se de técnicas capazes de aproximarem máquinas a padrões cognitivos

\footnotetext{
${ }^{7}$ Sobre as iniciativas das licenças creative commons e do movimento de acesso livre, vide: Feres e Oliveira (2016). Sobre as repercussões do movimento de software livre para o plano de programas de computador, vide: Feres et al. (2018). Devido ao recorte da pesquisa, as licenças creative commons, o movimento de acesso livre e de software livre não serão abordados em pormenor.
} 
presentes em humanos e/ou em animais. Este autor assevera que a ideia de sistemas com inteligência artificial não é recente, uma vez que estudos da segunda metade do século passado já os previam. Contudo, os tempos cibernéticos trouxeram a evolução da capacidade computacional para processar dados e uma consequente atenção política de Estados para com este fenômeno.

Ainda conforme Calo (2017, p. 02-5), a explosão na capacidade de produzir e gerenciar dados fez surgir um importante segmento da inteligência artificial - o dos mecanismos de aprendizado de máquina (machine learning) -, hábil a aprimorar a capacidade de performance de sistemas computadorizados em tarefas voltadas ao reconhecimento de padrões. O fenômeno, em sua fase incipiente, tem se concentrado a partir de projetos de gigantes da internet, como Google, Baidu, Facebook, Microsoft, Apple, IBM e Amazon.

De acordo com Ramalho (2017, p. 02-5), dada a capacidade criativa destes sistemas, uma das principais preocupações legais com a inteligência artificial consiste no conceito legal de autor, semanticamente associado à figura humana. Segundo a pesquisadora, a figura do criador está ligada às faculdades de inteligência e de autonomia. Inteligência envolve o atributo de criatividade, formado pela capacidade do autor de julgar, manter padrões aleatórios em suas criações e possuir autocrítica para os resultados de seu trabalho. A autonomia está associada à capacidade autossuficiente de criar certas obras em dada escala. Ambos os conceitos são de complexa visualização para programas baseados em inteligência artificial, o que suscita o surgimento de diversas teorias ${ }^{8}$ para definir a titularidade de obras criadas neste contexto.

As vantagens da inteligência artificial podem ser observadas em inúmeras expertises humanas, especialmente para potencializar a capacidade de criar obras marcadamente autorais, como músicas, vídeos ou livros. Hristov (2017, p. 433-6) aponta que o segmento generativo de inteligência artificial é formado por iniciativas de auxílio à criação ou de elaboração autônoma de obras autorais. Assim, por exemplo, estes sistemas podem tanto mediar o desenvolvimento de uma pintura de arte, ao conceber um resultado a partir de critérios pré-determinados por um artista, quanto gerar seus próprios padrões de desenho, a partir dos dados que o alimentam.

Já Levendowski (2018, p. 593-630) demonstra que a importância do direito autoral para a inteligência artificial reside além da mera discussão de titularidade de uma criação: ela se

\footnotetext{
${ }^{8}$ Chiabotto sintetiza oito teorias que tentam resolver o problema de obras autorais elaboradas por um sistema baseado em inteligência artificial: os direitos de exclusivo da obra poderiam pertencer (a) ao domínio público, (b) à máquina, se atribuída uma personalidade jurídica, (c) à máquina e ao humano responsável por operá-la, em conjunto, (d) à uma personalidade humana ficta, cujos direitos autorais seriam fragmentados entre agentes identificados nos casos concretos, (e) ao programador, (f) ao usuário, (g) ao programador e ao usuário em conjunto e (h) ao empregador contratante (CHIABOTTO, 2017, p. 14-8).
} 
relaciona ao atributo de enviesamento de sistemas artificiais. O sucesso de uma ferramenta fundada em inteligência artificial está umbilicalmente ligado à disponibilidade de dados para treinar os seus resultados e estes dados devem ser diversos o bastante para assegurar respostas não enviesadas, tendenciosas ou discriminatórias. Assim, é imprescindível repensar o papel do direito autoral no contexto de disponibilidade das obras por ele protegidas com vistas a viabilizar a competição e o acesso justo e variado de fontes, diversificando as criações decorrentes e promovendo o respeito humano.

Um último e importante conceito a ser ressaltado no tema da inteligência artificial, com implicações imediatas ao direito autoral, é o de singularidade tecnológica. Leou-On (2014, p. $43 ; 70$ ) elucida a singularidade como um ponto histórico de "explosão repetitiva da inteligência", cujas inovações e invenções atingirão níveis exponenciais, em uma espécie de ciclo de recorrentes de efeitos positivos.

Para Leou-On, tal incremento - oriundo dos avanços de sistemas com inteligência artificial, da conexão entre a mente humana e a máquina e do incremento do corpo biológico levará os novos descobrimentos científicos a uma escala "trivial e rápida", numa expansão instantânea e infinita de realizações e desenvolvimentos. Destarte, para o autor, tal fenômeno, a ser presenciado em um breve futuro, invoca a necessidade atual de discussão e fixação de balizas éticas ao desenvolvimento tecnológico (LEOU-ON, 2014, p. 43; 70). O direito autoral, frente a este cenário de infinitas possibilidades criativas, será mais uma vez testado aos seus limites para regular formas ainda não previstas de uso de obras intelectuais.

Em suma, torna-se notório o potencial disruptivo contido em tecnologias cujo desenvolvimento se dê a partir da inteligência artificial. Para os direitos autorais, tal evolução traz questões a nível de titularidade, de acesso aos bens intelectuais e de proteção a novas formas de expressão não adstritas à personalidade humana.

\subsubsection{Contratos inteligentes e direitos autorais}

Uma outra tecnologia com potencial disruptivo à aplicação dos direitos autorais é a dos chamados contratos inteligentes (ou smart contracts). A noção de formar um contrato por meios eletrônicos com o auxílio da rede de computadores foi realçada desde os primórdios da evolução comercial da arquitetura da web. Em pleno ano de 1994, Szabo já havia explorado a ideia de incorporar cláusulas contratuais a um protocolo computadorizado. Seu intuito era o de criar estruturas eficientes e autoexecutáveis, capazes de desestimular o descumprimento contratual e 
diminuir os custos de transação em relações formalizadas, com o auxílio de instrumentos digitais (SZABO, 1994).

Como destacam Wright e Filippi (2015, p. 10-3), a aplicação dos smart contratcts permitirá tanto que contratos sejam formalizados pela via computacional, em observância a parâmetros legais e sem o risco de ambiguidades jurídicas, quanto que se viabilize a implementação automatizada de obrigações, sem nenhum suporte contratual legal subjacente. No campo das obras protegidas por direito autoral, os pesquisadores exemplificam a possibilidade de tornar sistemas de remuneração de músicas gerenciáveis de forma instantânea, mediante o controle de distribuição de cada cópia a artistas e a compositores.

Consoante Verstraete (2018, p. 12-4), o conceito de contratos inteligentes exposto por Szabo partia basicamente de uma noção automatizada de contrato, viabilizada por meio da tecnologia, tal como ocorre em uma máquina automática de venda de lanches e refigerantes . Em tais tipos de máquina, a inserção de uma moeda ou cédula funciona como um gatilho contratual para a venda do produto desejado.

Desse modo, este autor afirma que foi a partir do surgimento de uma nova tecnologia, o blockchain, que a abstração de Szabo pôde ser revivida e implementada de uma forma mais concreta (VERSTRAETE, 2018, p. 13). Em seu turno, Savelyev (2016, p. 06) vai mais além e afirma que a tecnologia do blockchain passa a expressar não somente uma aplicação mais factível, como um atributo nuclear dos contratos inteligentes. É, portanto, a partir dessa conexão que se passa a analisar o terceiro tipo de tecnologia disruptiva à aplicação dos direitos autorais, o blockchain.

\subsubsection{Blockchain e direitos autorais}

Em um artigo escrito em 2008 e que atingiu a marca de mais de 5.700 (cinco mil e setecentas) citações (GOOGLE SCHOLAR, 2019), um [anônimo] autor apresentado por Satoshi Nakamoto (2008, p. 01-9) apresentou o conceito e a forma de organização de um sistema de transações eletrônicas pessoa a pessoa. Tal sistema seria capaz de substituir a necessidade de confiança em autoridades centrais - como instituições bancárias - por criptografia descentralizada. Com essa ideia surge a moeda virtual bitcoin e uma rede subjacente de registros distribuídos, conhecida como blockchain ${ }^{9}$.

\footnotetext{
${ }^{9}$ Kakavand et al. (2017, p. 14-20) citam algumas das possíveis aplicações dessa rede de registros, como: realização de transações financeiras de forma rápida, sem a intermediação de terceiros, como bancos; desenvolvimento de contratos inteligentes, executados de forma automática a partir do cumprimento de certas
} 
O invento seria executado a partir da sistematização prática de conceitos basilares expostos por Nakamoto (2008, p. 01-9), como: funções hash (algoritmos matemáticos que transformam um grande volume de informação em sequências numéricas de tamanho fixo, verificáveis por assinaturas eletrônicas), servidores timestamp (servidores computadorizados públicos capazes de estabelecer um selo temporal nas funções matemáticas, de maneira a resolver eventuais duplicações e a formar uma cadeia sequencial), sistema proof-of-work (sistema que liga os selos temporais de hashs à rede de computadores, validando informações em sequência, de modo que cada bloco de informações interligado confirma o anterior, sendo que qualquer tentativa de alterar os registros precisaria mobilizar a capacidade de processamento de toda a rede) e uma rede de redistribuição honesta de consenso (onde os "nós" - pontos de redistribuição dos blocos de informação - seriam incentivados a operar a sua capacidade de processamento e de armazenamento em função de validar criptograficamente os registros, recebendo recompensas, como taxas de processamento, por atestarem a confiabilidade das transações e rejeitarem operações inválidas).

De acordo com Savelyev (2017, p, 04), no que tange à habilidade de acesso e de realização de transações, as redes de registro blockchain se distribuem em duas grandes categorias: permissionless (apermissionadas) e permissioned (permissionadas). No primeiro caso, a estrutura de organização de uma rede, como o Bitcoin $^{10}$, torna possível a todos os usuários realizarem transações sem necessidade de consentimento de uma autoridade central. Já no segundo caso, se permissionadas, como a rede Hiperledger Fabric ${ }^{l 1}$, há um operador da rede de blocos capaz delimitar diferentes graus de acesso e uso apenas a usuários e desenvolvedores autorizados. $\mathrm{O}$ autor infere que, embora uma rede permissionada seja, em princípio, contraditória ao propósito colaborativo, livre e descentralizado que fez surgir o blockchain, ela ainda mantém o caráter de transparência e resiliência contra ataques.

Tresise et al. (2018, p. 02) sustentam que as premissas de aplicação do blockchain para as obras autorais não seriam, a princípio, de armazenar o material protegido em si, haja vista

condições; registros de venda e aluguel de propriedades imobiliárias; acompanhamento do processo de desenvolvimento e entrega de medicamentos a pacientes em cuidados médicos; gestão pública de governos inteligentes, auxiliando na emissão de registros públicos como passaportes ou carteiras de motorista, na cobrança de impostos e em sistemas de votação; e integração com sistemas de inteligência artificial no ambiente de dispositivos conectados pela internet (IoT)

${ }^{10}$ Rede de pagamentos e de sistema monetário descentralizado, baseada em tecnologia blockchain (BITCOIN, 2019).

${ }^{11}$ Rede de colaboração de negócios baseada em tecnologia blockchain, gerenciada pela Linux Foundation (2019). 
possíveis problemas com o tamanho e a forma de arquivamento de certos conteúdos, mas sim de registrá-los de forma pública, transparente e única no tempo e espaço.

Os autores identificam cinco principais aplicações nas quais esta tecnologia pode auxiliar a enfrentar dilemas contemporâneos de conteúdos protegidos por direitos autorais: (a) sistemas de registros de informações sobre obras autorais, (b) gerenciamento de direitos digitais ou DRM, (c) licenciamento de obras, (d) organizações de gestão coletiva de direitos autorais e (e) trabalhos órfãos (TRESISE et al., 2018, p. 03-14).

Para o problema de registro de informações, os autores lembram que os direitos autorais comumente não estipulam o registro da obra em órgãos oficiais como requisito de concessão e que há recorrentes dificuldades em identificar a autoria e os limites legais de uso de uma obra. Assim, o blockchain pode facilitar na obtenção de informações sobre a obra, sua titularidade e sua situação legal, o que é ainda mais interessante para o caso de obras em domínio público ou com licenças permissivas, tais como creative commons.

Com relação ao segundo problema, da gestão de direitos digitais, os autores recordam que as tecnologias de controle de uso de obras autorais em vigência são ineficientes e o blockchain seria capaz de viabilizar contratos inteligentes criptografados com termos e autorizações de uso para cada cópia, sem depender de mecanismos proprietários voláteis. Em respeito ao terceiro problema, do licenciamento das obras, o registro descentralizado poderia ser capaz de mitigar a necessidade de intermediários e dar um maior poder de negociação ao criador de conteúdo.

Já para a quarta questão, das organizações coletivas de gerenciamento, o blockchain viabilizaria também a criação destas instâncias grupais de administração de direitos - com custos mais acessíveis e capazes de reunir catálogos de obras, aproximando autores e usuários -, uma vez que eliminar todo e qualquer intermediário do contexto das obras autorais pode ser impraticável. Por fim, para o caso dos trabalhos órfãos - aqueles em que o autor não pode ser identificado por motivos variados - os registros de blockchain poderiam tornar mais fáceis a indexação de obras e autores, bem como criar um sistema de verificação de autoria, que funcionaria como prova de diligência do terceiro no uso de uma obra órfã (TRESISE et al., p. 03-14).

Em síntese, o uso isolado ou combinado destas tecnologias de sistemas de inteligência artificial, contratos inteligentes e blockchain são capazes de transformar todo o modo de uso de obras autorais tal como se conhece hodiernamente. A partir das quatro categorias expostas por Lessig (2006, p. 122-7), é possível constatar a interação das dimensões de mercado e da arquitetura para moldar a dimensão dos usos sociais de obras autorais. Mercado e arquitetura 
ainda contam com o apoio (parcial) da lei, ao menos em sua dimensão exclusivista, para interferir nas normas sociais relativas ao uso de bens digitais e conceder todos os direitos a autores e empresas.

Logo, o que as tecnologias supramencionadas prometem para o âmbito dos direitos autorais é o emprego de códigos, ou arquiteturas tecnológicas, para automatizar o processo de registro, uso e transferência de direitos em obras variadas. Se o entusiasmo com tais possibilidades deve ser incentivado, a próxima seção levanta questionamentos mais profundos a partir do caso do gerenciamento de direitos digitais, investigando os limites na confiança irrestrita nos códigos tecnológicos.

\section{O QUE O PASSADO PODE NOS ENSINAR: DIGITAL RIGHTS MANAGEMENT E OS LIMITES DA GOVERNANÇA POR CÓDIGO}

Até aqui viu-se que o surgimento das tecnologias disruptivas de inteligência artificial, contratos inteligentes e blockchain é capaz de, isoladamente ou em conjunto, trazer vários benefícios e desafios à aplicação dos direitos autorais. O objetivo da presente seção é o de analisar uma premissa comum destas tecnologias: a de usar códigos tecnológicos para garantir e limitar comportamentos humanos. Para tanto, passa-se à investigação de elementos comuns das tecnologias de gerenciamento de direitos digitais, em vigência nas últimas décadas, e das lições que deles podem ser extraídas.

De acordo com Camp (2012, p. 02; 07-8), as prerrogativas de restrição de acesso dos direitos autorais não se esgotam na dimensão legal. Nesse sentido, os sistemas de DRM são nada mais do que um mecanismo para assegurar os direitos autorais em bens digitais. Entre exemplos de aplicação do DRM, o autor traz um clássico: o chamado Content Scrambling System (CSS), inovação presente nos aparelhos de DVD no início dos anos 2000, que consistia em um identificador geográfico de dispositivos e de mídias. O CSS empregava criptografia para controle de mídias e seu propósito original era o de funcionar como um fixador geográfico, capaz de auxiliar empresas a discriminarem os preços daqueles aparelhos e de suas unidades de leitura em diferentes mercados. Todavia, ele se desdobrava em uma ferramenta prática de restrição ao uso de cópias, travando a execução de mídias ou aparelhos oriundos de zonas geográficas distintas. Como o autor explica, tal sistema se formou como resposta da indústria audiovisual à pirataria, a qual começava a ganhar os holofotes. 
Como explica Cohen (2003, p. 06-14), as técnicas de DRM têm por intuito direcionar os comportamentos dos usuários no consumo de bens virtuais. A autora identifica três grandes eixos gerais de aplicação dessas tecnologias: (a) limitar, (b) monitorar e (c) direcionar. Pela primeira característica, os sistemas de DRM estabelecem e tolhem as liberdades de uso do consumidor de um bem digital. Um sistema de DRM pode, por exemplo, autorizar a leitura de uma obra, mas bloquear a sua edição. Pelo monitoramento, estes sistemas enviam relatórios automatizados acerca atividades do usuário no consumo daquele bem. Já pela característica do direcionamento, decorrente das anteriores, os sistemas de DRM podem embutir protocolos para reforçar consequências contra um uso indesejado, a exemplo de fechar um programa como penalidade por detectar o uso não autorizado de uma mídia.

Consideradas como invasivas à privacidade e à autonomia dos consumidores de mídias, as tecnologias de Digital Rights Management chegaram a receber o apelido pejorativo de Digital Restrictions Management, ou gerenciamento de restrições digitais, em um trocadilho com o significado da letra R na sigla em inglês (FREE SOFTWARE FOUNDATION, 2016). Jaisingh (2007, p. 331) ainda observa que o uso dessas tecnologias é manipulável conforme o interesse de mercado das empresas detentoras de direitos sobre obras virtuais, com flexibilização do seu uso no momento de ingresso e austeridade após atingidas as metas de expansão de clientes.

Em estudo empírico e voltado para os dilemas de sistemas de DRM na indústria de videogames, Favale et al. (2016, p. 299-304) constataram que a principal limitação no uso dessa tecnologia não está necessariamente em arquiteturas tecnológicas, mas sim no elemento humano: sua implementação tem por foco assegurar os direitos de criadores e empresas no uso de suas obras digitais, mas desconsideram como o público recepciona e reage a tais medidas.

Os autores argumentam que estes sistemas precisam de equilíbrio quanto aos atores envolvidos em seu desenvolvimento e em seu uso, além de clareza quanto aos reflexos jurídicos. O equilíbrio deve ocorrer ao salvaguardar não somente o prisma das (1) distribuidoras de conteúdos autorais, mas também de (2) desenvolvedores e (3) usuários. E a clareza deve se desenvolver em observância não somente às diretrizes exclusivas dos direitos autorais, mas aos seus limites internos e externos por parte de outros direitos e prerrogativas lícitas de uso (FAVALE et al., 2016, p. 299-304).

Tresise et al. (2018, p. 06-8) ainda apontam que o DRM pode ganhar sobrevida no ambiente de contratos automatizados e de blockchain. Por um lado, a incorporação via blockchain poderia ser vantajosa, uma vez que as medidas de controle e restrição de usos estariam mais padronizadas no registro descentralizado público, portanto, menos sujeitas às oscilações de medidas imprevisíveis por parte de empresas e entes privados. Além disso, 
contratos inteligentes poderiam ser implementados via criptografia de chaves públicas e privadas, de maneira a dar maior precisão nas prerrogativas de uso, em consonância aos termos de uma licença. Por outro lado, a implementação via blockchain poderia gerar dificuldades em fixar os limites internos e externos aos direitos autorais. Logo, usos lícitos, mas não previstos por um sistema, poderiam ser bloqueados de forma arbitrária.

É justamente neste ponto em que o caso do DRM pode trazer uma importante lição para as novas tecnologias de execução automática de transações. Antes de se falar em arquitetura ou em código conforme os interesses do mercado, é necessário relembrar, pelo prospecto teórico de Lessig (2006, p. 122-9), que existem mais duas dimensões que precisam ser consideradas para o sucesso destas medidas: a da lei e a das normas sociais. Aqui fala-se, sobretudo, em governança e a sua relação necessária com a tecnologia.

Verstraete (2018, p. 06-7) esclarece que tecnologias com o caráter disruptivo, como a internet ou os contratos inteligentes, apresentam três nuances: (I) não afastam a importância e papel do Estado na regulação das relações privadas, (II) inviabilizam a aplicação de regras neutras impressas em código, uma vez que a neutralidade não é possível e (III) suplantam instituições democráticas em favor de um exercício excessivo e ilegítimo de autotutela exclusiva de direito autoral.

No mesmo sentido, por governança, Mulligan e Bamberger (2018, p. 783-4) explicam que soluções baseadas em códigos tecnológicos precisam passar por um processo de florescimento e debate democrático de seus contornos, uma vez que nenhum código é neutro.

Em síntese, estes últimos autores apontam os seguintes problemas das regras por design: (I) a ausência de flexibilidade e controle de consequências nas medidas reforçadas por código tecnológico, a exemplo de ações em prol do combate à pirataria, capazes de provocar mudanças e prejuízos à liberdade de uso de obras na internet; (II) a eleição particular de certos valores, como os patrimoniais, em detrimento de outros valores publicamente legítimos, como os direitos humanos de acesso ao conhecimento e de educação; (III) a insuficiência de conhecimento por parte de agências e órgãos reguladores em lidar com ferramentas técnicas necessárias para estatuir o design por código, a exemplo de agências governamentais inaptas a regularem práticas de gigantes da tecnologia; (IV) e a omissão política no processo de tomada de decisões, a exemplo de normas que afetam a sociedade sendo tomadas por entes privados sem transparência e sob uma [insustentável] prerrogativa neutra ou apolítica (MULLIGAN; BAMBERGER, 2018, p. $739-742)$.

Feitas todas estas considerações, o que o caso da gestão de direitos digitais revela é que o potencial disruptivo de tecnologias que empregam inteligência artificial, contratos inteligentes 
ou blockchain para gerir ou promover obras autorais não é um assunto novo. Muito embora seja plenamente justificável o entusiasmo com as possibilidades trazidas por estes avanços tecnológicos, é pertinente ressaltar que há um princípio basilar já notório por detrás de tais criações: o de fazer com que a arquitetura tecnológica, manejada por interesses como os de mercado, module e determine o uso humano de obras intelectuais.

No entanto, como ensina o postulado da afirmativa teórica escolhida a partir de Lessig (2006, p. 122-7), não só o mercado e a arquitetura são capazes de influenciar comportamentos humanos para o uso de obras no meio virtual: é necessário levar em conta a harmonia com provisões legais e normas sociais que regem o gozo de tais criações.

No plano legal, faz-se urgente rediscutir e reavaliar os contornos de tais tecnologias frente aos pressupostos da lei brasileira de direitos autorais, com suas vantagens e desvantagens, bem como considerar a unidade de princípios e valores democraticamente consagrados no ínterim de nosso ordenamento jurídico.

Desse modo, as constatações de equilíbrio entre as funções promocional e social dos direitos autorais, expostas por Souza (2011, p. 664-6) e a compreensão dos feixes patrimonial e moral desses direitos, apresentados por Branco (2013, p. 24-6) são balizas importantes para vislumbrar que o controle puro da exclusividade patrimonial da obra não esgota o sentido dos direitos autorais. Da mesma maneira, iniciativas legais, como os movimentos de creative commons, de acesso livre e de copyleft trouxeram importantes contribuições e redefinições a este debate, cujos benefícios precisam ser reverberados.

A necessidade de atenção à dimensão social dos direitos autorais instiga Eklin-Koren (2017, p. 1.093-1.100) a argumentar pela defesa do chamado fair use por design. A doutrina do fair use, ou do uso justo, defende em síntese uma concepção equilibrada do direito autoral, em que o incentivo à criação deve ocorrer não somente pela proteção ao autor, mas também ao salvaguardar as liberdades dos usuários, em privilégio à criatividade humana. De tal forma, a autora defende a aplicação desses pressupostos ao plano do design tecnológico, para assegurar a liberdade de expressão e de acesso ao conhecimento. Tal tarefa demandaria o comprometimento integrado de programadores, engenheiros, juristas e acadêmicos.

A um primeiro momento, pode-se argumentar que a doutrina do uso justo não guarda relação com a ordem jurídica brasileira, dada a sua peculiaridade de construção casuística no ordenamento de common law norte-americano. Porém, a noção de uso justo chegou até a ser defendida pela própria Associação Brasileira de Propriedade Intelectual, a partir Resolução ${ }^{\circ}$ 67, cuja proposta era a de alteração do artigo 46 da Lei de Direitos Autorais. Tal resolução trazia 
a inclusão de diretrizes ${ }^{12}$ internas de limitação às prerrogativas do direito de exclusivo, mais flexíveis e compatíveis à sociedade da informação.

No plano social, a necessidade de conjugar os interesses de todos os envolvidos com os processos de restrição de uso de obras, exposta por Favale et al. (2016, p. 299-304), demonstra que a premissa da regulação por código carrega desdobramentos os quais precisam ser avaliados não só por desenvolvedores, mas por distribuidores de conteúdos e por usuários na sociedade da informação.

Como visto, medidas de controle de obras intelectuais digitais, como o DRM, passam por um processo refinado de elaboração técnica, porém, muitas vezes não levam em conta os reflexos de sua recepção social e mercadológica.

Neste ponto, um último exemplo a se mencionar é o do desenvolvimento da indústria de videogames no Brasil que, como demonstram Haddad e Falcão (2016) na série Paralelos, ocorreu às margens dos esforços de controle da lei e da arquitetura de código, privilegiando a cooperação e a distribuição descentralizada. A série demonstra que vários consoles e jogos não licenciados ganharam o gosto social, abrindo caminho para as sofisticadas e agora legalizadas plataformas de videogame. Tal mercado, contudo, poderia ter sofrido rumos diferentes não fosse sua formação às margens da lei e das grandes empresas em décadas passadas. $\mathrm{O}$ caso exposto na série demonstra a força dos usos sociais em plena era conectada, capaz de estimular mercados e até de fomentar o desprezo por legislações de propriedade intelectual, como ocorre com a pirataria de mídias.

Portanto, para o direito autoral, a síntese das possibilidades e problemas que podem erigir a partir da inteligência artificial, dos contratos inteligentes e do blockchain precisa sempre considerar o que a experiência do DRM já ensinou: a governança por código deve ser arquitetada

\footnotetext{
${ }^{12}$ Nova proposta de redação do artigo 46 da LDA, segundo a Resolução 67 da ABPI:

Art. 46. Não constitui ofensa aos direitos autorais, a reprodução parcial ou integral, a distribuição e qualquer forma de utilização de obras intelectuais que, em função de sua natureza, atenda a dois ou mais dos seguintes princípios, respeitados os direitos morais previstos no art. 24: I - tenha como objetivo, crítica, comentário, noticiário, educação, ensino, pesquisa, produção de prova judiciária ou administrativa, uso exclusivo de deficientes visuais em sistema Braile ou outro procedimento em qualquer suporte para esses destinatários, preservação ou estudo da obra, ou ainda, para demonstração à clientela em estabelecimentos comerciais, desde que estes comercializem os suportes ou equipamentos que permitam a sua utilização, sempre na medida justificada pelo fim a atingir; II - sua finalidade não seja essencialmente comercial para o destinatário da reprodução e para quem se vale da distribuição $\quad$ e $\quad$ da $\quad$ utilização $\quad$ das obras III - o efeito no mercado potencial da obra seja individualmente desprezível, não acarretando prejuízo à exploração normal obra; Parágrafo Único - A aplicação da hipótese prevista no inciso II deste artigo não se justifica somente pelo fato de o destinatário da reprodução e quem se vale da distribuição e da utilização das obras intelectuais ser empresa ou órgão público, fundação, associação ou qualquer outra entidade sem fins lucrativos (ABPI, 2005).
} 
não somente para atender aos desejos dos entes de mercado, ela necessita incorporar valores sociais abrangentes contidos na ordem democrática geral, bem como balancear as formas de uso de bens digitais na sociedade. Não por acaso, Mulligan e Bamberger (2018) defendem "salvar"13 a governança por design a partir do florescimento democrático de sua construção. A lição extraída é a de que as arquiteturas de códigos em tecnologias não são neutras e precisam ser debatidas e avaliadas de forma pública.

\section{CONSIDERAÇÕES FINAIS}

Esta pesquisa visou a, em nível teórico e qualitativo, discutir a relação entre tecnologias disruptivas e suas repercussões com as dimensões e propósitos dos direitos autorais. Utilizandose das lições extraídas a partir das experiências de DRM, investigou-se os possíveis desdobramentos das tecnologias baseadas em inteligência artificial, contratos inteligentes e blockchain para o plano regulatório de criações autorais.

A afirmativa teórica utilizada como pressuposto para a análise foi a dos quatro modelos de regulação dos comportamentos humanos, expostos por Lawrence Lessig, a saber, lei, normas sociais, mercado e arquitetura. O modelo metodológico de discussão empregou uma investigação qualitativa interdisciplinar a partir de referenciais bibliográficos disponíveis.

Constatou-se que, embora tenha potenciais ainda inexplorados e não calculados, a aplicação das tecnologias investigadas possui um viés compartilhado de automatização codificada do comportamento humano. A exemplo do caso do gerenciamento de direitos digitais e sua relação com o direito autoral é possível constatar uma expectativa de praticidade tecnológica, a qual seria capaz de regular, por si só, o uso de criações intelectuais. Tal promessa, porém, não respeitará as aspirações do direito autoral sem o devido debate público acerca da governança de tais tecnologias e de seus respectivos reflexos legais e sociais.

Destaca-se, por fim, que a intenção deste artigo não é a de depreciar os incontáveis novos usos de obras autorais que poderão ser fomentados a partir da aplicação isolada ou em conjunto

\footnotetext{
${ }^{13}$ Para atingir esta proposta, os autores constroem quatro regras de engajamento fundamentais à governança por código, sintetizadas da seguinte maneira: (1) que haja o estabelecimento de parâmetros moderados de design, os quais fixem limites às aplicações tecnológicas sem prejuízo da flexibilidade necessária das atividades empresariais, privilegiando o controle de implicações, a autonomia de escolhas dos usuários e a adaptabilidade; (2) que direitos humanos e direitos de ordem pública sejam balanceados flexivelmente junto a direitos econômicos e não a estes subalternos; (3) que as autoridades reguladoras e o processo legislativo sejam redesenhados internamente e melhor assessorados externamente para fundar ferramentas coordenadas na tomada de decisões; (4) e que os processos de decisão por código ganhem maior transparência, assegurando o mínimo de confiabilidade por meio de ferramentas de controle, auditoria e verificação de suas conclusões (MULLIGAN; BAMBERGER, 2018, p. 742-783).
} 
da inteligência artificial, dos contratos inteligentes e do blockchain. $\mathrm{O}$ intuito foi o de alertar para o fato de que o debate disruptivo sempre esteve na dimensão estrutural dos códigos tecnológicos e que tal dimensão é fomentada por importantes agentes de mercado, cujas práticas (legítimas ou não) devem ser incorporadas ao debate legal e social de uma maneira mais fluida, dinâmica e democratizada.

Por conseguinte, a reflexão derradeira suscitada por este artigo é a de que, se o tempo não para, o futuro disruptivo dos direitos autorais pode se desdobrar, tal como na música de Brandão e Cazuza (1988), em um museu de grandes novidades, no qual o futuro pode repetir o passado: onde há entusiasmo (e o temor) pelo design tecnológico, sempre houve a necessidade de um olhar mais atento e democrático acerca do papel da tecnologia na interação com a vida humana.

\title{
THE FUTURE REPEATING THE PAST? DIGITAL RIGHTS MANAGEMENT, DISRUPTIVE TECHNOLOGIES AND THE BRAZILIAN COPYRIGHT SYSTEM
}

\begin{abstract}
This paper aims to analyze some disruptive technologies, namely, artificial intelligence, smart contracts and blockchain, and investigate, through the Digital Rights Management (DRM) case, the main lessons and challenges posed to copyrighted intellectual goods in the so-called Digital Age. Both Groulx's qualitative analysis concept and Lessig's idea of four modalities of human constraint compose the methodological and theoretical framework. Through the DRM case study, the research concludes that copyright applied to artistic creations needs to be re-evaluated in order to enhance practical public and democratic frameworks. In these lines, despite their relevant inner innovations, artificial intelligence, smart contracts and blockchain technologies suffer a lack of broader social and legal engagement.
\end{abstract}

Keywords: Blockchain. Smart Contracts. Copyright. Artificial Intelligence. Digital rights management. 


\section{REFERÊNCIAS}

ABPI. Resolução Nº 67, Direito Autoral -Limitações ao Direito de Autor. Associação Brasileira de Propriedade Intelectual, out. 2005. Disponível em: $<$ http://www.abpi.org.br/biblioteca2a.asp?Ativo=True\&linguagem=Portugu\%Eas\&secao=Bibl ioteca\&subsecao=Resolu\%E7\%F5es\%20da\%20ABPI\&id=2>. Acesso em: 01 out. 2018.

BITCOIN. Getting Started with Bitcoin, 2019. Disponível em: <https://bitcoin.org/en/gettingstarted:. Acesso em: 09 fev. 2019.

BOLDRIN, Michele; LEVINE, David K. Against Intellectual Monopoly. Final Online Version, jan. 2008, 323 p. Disponível em: <http://levine.sscnet.ucla.edu/papers/imbookfinalall.pdf $>$. Acesso em: 03 set. 2018.

BRANCO, Sérgio. A natureza jurídica dos direitos autorais. Civilistica.com. Rio de Janeiro, v. 2, n. 2, p. 01-26, abr./jun. 2013. Disponível em: $<$ http://civilistica.com/a-natureza-juridica-dosdireitos-autorais/>. Acesso em: 20 set. 2018.

BRANDÃO, Arnaldo; CAZUZA. O Tempo não Para. Intérprete: Cazuza. In: CAZUZA. $O$ Tempo não Para. Rio de Janeiro: Polygram e Universal Music, 1988. 1 CD (37 min 20 s). Faixa 06 (04 $\min 37 \mathrm{~s})$.

BRASIL. Lei 9.610, de 19 de Fevereiro de 1998. Altera, atualiza e consolida a legislação sobre direitos autorais e dá outras providências, 1998. Disponível em: $<$ http://www.planalto.gov.br/ccivil_03/leis/L9610.htm>. Acesso em: 03 set. 2018.

CALO, Ryan, Artificial Intelligence Policy: A Primer and Roadmap. Social Science Research Network, p. 01-28, 2017. Disponível em: <http://dx.doi.org/10.2139/ssrn.3015350>. Acesso em: 28 ago. 2018.

CAMP, L. Jean. DRM: Doesn't Really Mean Digital Copyright Management. KSG Working Paper Series RWP02-034, p. 78-87, ago. 2012. Disponível em: $<$ http://dx.doi.org/10.1145/586110.586122>. Acesso em: 01 set. 2018. 
CHIABOTTO, Alessio. Intellectual Property Rights Over Non-Human Generated Creations

Social Science Research Network, p. 01-18, 2017. Disponível em: $<$ http://dx.doi.org/10.2139/ssrn.3053772> . Acesso em: 28 set. 2018.

CHRISTENSEN, Clayton M. The Innovator's Dilemma. Nova Iorque: HarperCollins, 1997, 286 p.

COHEN, Julie E. DRM and Privacy. Berkeley Technological Law Journal, v. 18, p. 575-617, 2003. Disponível em: < https://scholarship.law.georgetown.edu/facpub/60/>. Acesso em: 06 set. 2018.

ELKIN-KOREN, Niva. Fair Use by Design. UCLA Law Review, v. 64, p. 1082-1100, 2017. Disponível em: $\quad<$ https://www.uclalawreview.org/wpcontent/uploads/securepdfs/2017/09/Elkin-Koren-Article-64-5.pdf> . Acesso em: 27 set. 2018.

FAVALE, Marcella; MACDONALD, Neil; FAILY, Shamal; GATZIDIS, Christos. Human Aspects in Digital Rights Management: The Perspective of Content Developers. Social Science Research Network, p. 01-25, 2016. Disponível em: <http://dx.doi.org/10.2139/ssrn.2729199>. Acesso em: 28 out. 2018.

FERES, Marcos Vinício Chein; OLIVEIRA, Jordan Vinicius de; ABBAS DA SILVA, Lorena. Código-fonte, Linux e Supercomputadores: a relação entre Direito e Tecnologia. Revista Brasileira de Direito, Passo Fundo, v. 14, n. 1, p. 398-421, abr. 2018. Disponível em: $<$ https://doi.org/10.18256/2238-0604.2018.v14i1.2021>. Acesso em: 26 set. 2018.

FERES, Marcos Vinício Chein; OLIVEIRA, Jordan Vinícius de. Precisamos Falar sobre Copyright: o que Creative Commons, Open Access e Deep Web têm em comum? Revista de Propriedade Intelectual, Direito Contemporâneo e Constituição, v. 10, n. 03, p. 01-20, 2016. Disponível em: <http://dx.doi.org/10.16928/2316-8080.V10N03p.001-020>. Acesso em: 03 jan. 2018 .

FREE SOFTWARE FOUNDATION. Digital Restrictions Management and Treacherous Computing. Por John Sullivan, 2016. Disponível em: $<$ http://www.fsf.org/campaigns/drm.html>. Acesso em: 21 jul. 2018. 
GOOGLE SCHOLAR. Índice de citação do artigo: Bitcoin: a peer-to-peer eletronic cash system, de Satoshi Nakamoto, 09 fev. 2019. Disponível em: $<$ https://scholar.google.com.br/scholar?cites $=9372423383988544578 \&$ as_sdt $=2005 \&$ sciodt $=0$, 5\&hl=pt-BR>. Acesso em: 09 fev. 2019.

GRACZ, Katarzyna. Bridging the Gaps Between Social and Legal Norms Concerning Protection of Intellectual and Artistic Creations: On the Crisis of Copyright Law in the Digital Era. The Journal of World Intellectual Property, v. 16, n. 1-2, p. 39-57, 2013. Disponível em: $<10.1111 /$ j.1747-1796.2013.12005.x.>. Acesso em: 27 out. 2018.

GROULX, Lionel-H. Contribuição da Pesquisa Qualitativa à Pesquisa Social. In: POUPART, Jean. DESLAURIES, Jean-Pierre. GROULX, Lionel-H. LAPERRIÈRE, Anne. MAYER, Robert. PIRES, Álvaro. A Pesquisa Qualitativa: Enfoques Epistemológicos e Metodológicos. 3. ed. Petrópolis: Vozes, 2012, p. 95-124.

HADDAD, Hugo; FALCÃO, Pedro. Paralelos. Red Bull GmbH, 20 min 26 s, 2016. Disponível em: $\quad<$ https://www.redbull.com/br-pt/serie-paralelos-narra-pirataria-de-games-no-brasil $>$. Acesso em: 20 ago. 2018.

HRISTOV, Kalin. Artificial Intelligence and the Copyright Dilemma. IDEA: The Journal of the Franklin Pierce Center for Intellectual Propert, v. 57, n. 3, p. 431-454, 2017. Disponível em: $<$ https://ssrn.com/abstract=2976428>. Acesso em: 25 jul. 2018.

JAISINGH, Jeevan. Piracy on file sharing networks: Strategies for Recording Companies. Journal of Organizational Computing and Electronic Commerce, v. 17, n. 04, 2007. Disponível em: <https://doi.org/10.1080/10919390701636239>. Acesso em: 27 ago. 2018.

KAKAVAND, Hossein; DE SEVRES, Nicolette Kost; CHILTON, Bart. The Blockchain Revolution: An Analysis of Regulation and Technology Related to Distributed Ledger Technologies. Social Science Research Network, 2017. Disponível em: $<\mathrm{http} / / / \mathrm{dx}$. doi.org/10.2139/ssrn.2849251>. Acesso em: 05 set. 2018. 
LEMOS, Ronaldo. Creative Commons, mídia e as transformações recentes do direito da propriedade intelectual. Revista Direito GV, São Paulo, v. 01, n. 01, p. 181-187, mai. 2005. Disponível em: <http://hdl.handle.net/10438/2797>. Acesso em: 20 mai. 2018.

LEOU-ON, Yune. The Philosopher's Singularity. Social Science Research Network, 2014. Disponível em:<http://dx.doi.org/10.2139/ssrn.2649680>. Acesso em: 06 set. 2018.

LESSIG, Lawrence (2003). The Creative Commons. Dunwody Distinguished Lecture in Law, Florida Law Review, v. 55, jul. 2003. Disponível em: $<$ http://homepages.law.asu.edu/ dkarjala/OpposingCopyrightExtension/commentary/LessigCr eativeCommonsFlaLRev2003.htm>. Acesso em: 09 fev. 2019.

(2006). Code (version 2.0). Nova Iorque: Basic Books, 2006, 411 p. ISBN-10: 0-46503914-6. Disponível em: <http://codev2.cc/download+remix/>. Acesso em: 20 ago. 2018.

LEVENDOWSKI, Amanda. How Copyright Law Can Fix Artificial Intelligence's Implicit Bias Problem. Washington Law Review, v. 579, p. 580-630, 2018. Disponível em: $<$ https://ssrn.com/abstract=3024938. $>$. Acesso em: 20 set. 2018.

LINUX FOUNDATION. Hyperledger Fabric, The Linux Foundation Projects, 2019. Disponível em: <https://www.hyperledger.org/projects/fabric>. Acesso em: 09 fev. 2019.

LITOGRAFIA. In: Michaelis Moderno Dicionário da Língua Portuguesa. São Paulo: Editora Melhoramentos Ltda, $2016 . \quad$ Disponível $<\mathrm{http}$ ://michaelis.uol.com.br/busca? $\mathrm{r}=0 \& \mathrm{f}=0 \& \mathrm{t}=0 \&$ palavra=litografia $>$. Acesso em 02 de set. 2018.

MENELL, Peter S; SCOTCHMER, Suzanne. Intellectual Property. In: POLINSKY, A. Mitchell; SHAVELL, Steven. Handbook of Law and Economics, Forthcoming, UC Berkeley Public Law Research Paper n. 741724, 2005. Disponível em: <https://ssrn.com/abstract=741424>. Acesso em: 03 ago. 2018.

MULliGAN, Deirdre K; BAMBERGER, Kenneth A. Saving Governance-by-Design. California Law Review, v. 697, p. 697-784, 2018. Disponível em: 
$<$ https://ssrn.com/abstract=3175017>. Acesso em: 03 jul. 2018.

NAKAMOTO, Satoshi. Bitcoin: a peer-to-peer eletronic cash system. Bitcoin.org, 2008. Disponível em: <https://bitcoin.org/bitcoin.pdf>. Acesso em: 16 jul. 2018.

RAMALHO, Ana. Will Robots Rule the (Artistic) World? A Proposed Model for the Legal Status of Creations by Artificial Intelligence Systems. Social Science Research Network, jun. 2017. Disponível em: <http://dx.doi.org/10.2139/ssrn.2987757>. Acesso em: 20 jun. 2018.

SAVELYEV, Alexander (2016). Contract Law 2.0: «Smart» Contracts As the Beginning of the End of Classic Contract Law. Higher School of Economics Research Paper n. WP BRP 71, 2016. Disponível em: <http://dx.doi.org/10.2139/ssrn.2885241>. Acesso em: 09 fev. 2019.

(2017). Copyright in the Blockchain Era: Promises and Challenges. Higher School of Economics Research Paper n. WP BRP 77, 2017. Disponível em: $<$ http://dx.doi.org/10.2139/ssrn.3075246>. Acesso em: 09 fev. 2019.

SOUZA, Carlos Affonso Pereira de. O Domínio Público e a Função Social do Direito Autoral. Liinc em Revista, v. 7, n. 2, p. 664-680, set. 2011. Disponível em: $<$ http://revista.ibict.br/liinc/article/view/3314/2924>. Acesso em: 19 jul. 2018.

SZABO, Nick. Smart Contracts. Essays on Smart Contracts, Commercial Controls and Security, 1994. Disponível em: $<$ http://www.fon.hum.uva.nl/rob/Courses/InformationInSpeech/CDROM/Literature/LOTwinte rschool2006/szabo.best.vwh.net/smart.contracts.html>. Acesso em: 30 set. 2018.

TRESISE, Annabel; GOLDENFEIN, Jake; HUNTER, Dan. What Blockchain Can and Can't Do for Copyright. Australian Intellectual Property Journal, n. 144, 2018. Disponível em: $<$ https://ssrn.com/abstract=3227381>. Acesso em: 25 set. 2018.

VERSTRAETE, Mark. The Stakes of Smart Contracts. Arizona Legal Studies Discussion Paper n. 18-20, 2018. Disponível em: <https://ssrn.com/abstract=3178393>. Acesso em: 14 jul. 2018.

WRIGHT, Aaron; DE FILIPPI, Primavera. Decentralized Blockchain Technology and the Rise vol.12,nº.02, Rio deJaneiro, 2019. pp. 647-672 
of Lex Cryptographia. Social Science Research Network, p. 01-58, mar. 2015. Disponível em: $<$ http://dx.doi.org/10.2139/ssrn.2580664>. Acesso em: 06 ago. 2018.

ZITTRAIN, Jonathan L. The Generative Internet. Harvard Law Review, v. 119, 2006. Disponível em: <http://nrs.harvard.edu/urn-3:HUL.InstRepos:9385626>. Acesso em: 16 jun. 2018 .

Trabalho recebido em 29 de outubro de 2018 Aceito em 11 de fevereiro de 2019 